\title{
Changes in Diaphragm Thickness and 6-min Walking Distance Improvement After Inspiratory Muscle Training in Patients With Chronic Obstructive Pulmonary Disease
}

\section{Tomomi Ichiba ( $\nabla$ tomo330@ks.kyorin-u.ac.jp )}

Kyorin Daigaku - Inokashira Campus https://orcid.org/0000-0003-0635-489X

\section{Tetsuo Miyagawa}

Showa University: Showa Daigaku

\section{Toru Tsuda}

Tsuda University: Tsudajuku Daigaku

\section{Takeshi Kera}

Takasaki University of Health and Welfare: Takasaki Kenko Fukushi Daigaku

\section{Research}

Keywords: chronic obstructive pulmonary disease, inspiratory muscle training, diaphragm thickness, airway-occlusion pressure, pulmonary rehabilitation, POWER breathe Medic Plus, 6-min walking distance, health-related quality of life, dyspnea, COPD assessment test

Posted Date: June 28th, 2021

DOI: https://doi.org/10.21203/rs.3.rs-633562/v1

License: (c) (i) This work is licensed under a Creative Commons Attribution 4.0 International License. Read Full License 


\section{Abstract}

Background: The Global Initiative for Chronic Obstructive Lung Disease guidelines (http://www.goldcopd.org, accessed January 16,2020 ) reported the use of inspiratory muscle training (IMT) as a part of comprehensive respiratory rehabilitation programs for patients with chronic obstructive pulmonary disease (COPD). However, some studies have indicated that the effect of such training is uncertain. Moreover, it is unclear whether IMT effects are caused by improvement in central or peripheral factors. Few studies examining IMT effects have used new evaluation items. We aimed to clarify the effects of IMT by additionally measuring the airway-occlusion pressure at $0.1 \mathrm{~s}$ after the start of inspiratory flow $\left(\mathrm{P}_{0.1}\right)$, as an index of respiratory central output, and by evaluating diaphragm movement based on the thickness of the diaphragm muscle (Tdi) using ultrasound.

Methods: Thirteen patients with COPD participated in the study. IMT was performed using the POWER breathe ${ }^{\circledR}$ Medic Plus breathing trainer in combination with each participant's outpatient rehabilitation regimen. Starting at $20 \%$ of the maximal inspiratory pressure (PImax) and increasing to $50 \%$, the participants performed 30 IMT repetitions twice a day for 2 months. Respiratory muscle strength, $P_{0.1}, 6$ min walking distance (6MWD), and Tdi were measured before and after IMT. Dyspnea, lower limb fatigue (assessed using the Borg Scale), and respiratory rate (RR) were measured before and after the 6-min walk test (6MWT).

Results: PImax and 6MWD significantly increased after training. Tdi at resting inspiration and expiration and maximal inspiration also significantly increased after training. In addition, the Borg Scale scores for dyspnea and leg fatigue and the RR of the 1-min recovery period after the 6MWT significantly decreased. There was no significant difference in $\mathrm{P}_{0.1}$.

Conclusions: We examined the combined effects of IMT, incorporating the evaluation of $\mathrm{P}_{0.1}$ and Tdi. We found that the PImax, 6MWD, and Tdi significantly increased, but no significant difference was observed in $\mathrm{P}_{0.1}$ after training. These results suggest that the effects of IMT may be attributed to the improved peripheral factors rather than to the central factors.

\section{Background}

Pulmonary rehabilitation is centered on exercise therapy and is a combination of conditioning and daily living training activities. Respiratory muscle training is one of the fundamental disciplines in exercise therapy [1] and includes inspiratory (IMT) and expiratory muscle training; however, IMT is mainly performed $[2,3]$.

IMT is expected to improve respiratory muscle strength and endurance, exercise tolerance, dyspnea, respiratory function, daily living activities, and health-related quality of life (HRQOL) [4]. Currently, there are two IMT methods: one using an abdominal pad, and one using specific equipment. The abdominal pad method, which is well established, involves the placement of a heavy object on the abdomen while 
the patient is in the supine position to add inspiratory resistance $[5,6]$. There are two equipment methods: the inspiratory resistance load method and the hyperventilation method. The first method aims to increase the inspiratory muscle strength by contraction of the muscle at high strength and low speed. Devices, such as the P-flex, Threshold-IMT, and POWER breathe, are used in such cases [7]. In contrast, the second method aims to improve the endurance of the inspiratory muscle by contraction of the muscle at low intensity and high speed; devices, such as the incentive spirometer and Triflo区, are used in such cases.

Recently, a new tapered IMT device has been developed, in which the load pressure gradually decreases with the start of inspiration, while the airflow increases [8]. Because the pressure decreases gradually, the sense of effort also decreases. Therefore, the tapered IMT device gradually increases the resistance during the training period, thus, enhancing the strength and endurance of the inspiratory muscle more efficiently compared to a threshold-type device [9]. Currently, chronic obstructive pulmonary disease (COPD) is the most common target for respiratory muscle training [10, 11]; however, thoracic restrictive disease and neuromuscular diseases, such as muscular dystrophy, have also been reported as targets [12-14]. The Global Initiative for Chronic Obstructive Lung Disease (GOLD) guidelines (http://www.goldcopd.org, accessed January 16, 2020) recommended the incorporation of respiratory muscle training as part of a comprehensive respiratory rehabilitation program for COPD. In their metaanalysis of 32 studies including 830 cases of COPD, Gosselink et al. [15] revealed significant improvements in the maximal inspiratory pressure (PImax), respiratory muscle endurance, progressive load pressure, exercise tolerance, Borg Scale scores, dyspnea, and HRQOL after IMT. However, the effectiveness of IMT was limited and not as high as that of exercise therapy; nevertheless, IMT was effective in cases where the PImax was $\leq 60 \mathrm{cmH}_{2} \mathrm{O}$ and the load intensity was $\geq 30 \%$ of the PImax [15]. In another meta-analysis of 37 studies including 1,427 cases of COPD, which was conducted by Beaumont et al. [16], dyspnea, inspiratory muscle strength, and 6-min walking distance (6MWD) improved following IMT. However, it was reported that improvements in dyspnea were not related to respiratory muscle strength [16]. Langer et al. [17] reported that IMT improved the PImax and endurance in patients with COPD who have low PImax, and that it also reduced diaphragm electromyographic activity and respiratory discomfort.

Although the effect of IMT alone is recognized, some studies have examined the effect of respiratory muscle training in combination with exercise training [1]. In 2018, Charususin et al. [18] reported that PImax and respiratory muscle endurance improved after a combination of exercise and IMT. In contrast, other studies have reported no improvement in 6MWD, maximal exercise capacity, shortness of breath, HRQOL, grip strength, or number of steps. Beaumont et al. [19] discovered that, in patients diagnosed with GOLD "III" to "IV" COPD, only PImax differed between those who underwent respiratory rehabilitation and those who underwent IMT plus respiratory rehabilitation. Schultz et al. [20] compared respiratory rehabilitation with IMT in a cohort of 300 patients with COPD and 302 controls. They reported that only PImax and forced expiratory volume in $1 \mathrm{~s}\left(\mathrm{FEV}_{1.0}\right)$ were significantly better in the combination group. However, no significant differences were found in the 6MWD, COPD assessment test (CAT) scores, St. 
George's Respiratory Questionnaire scores, and Clinical COPD Questionnaire scores between the two methods [20].

Besides the contradictory results of previous studies regarding the effects of respiratory muscle training in combination with exercise training, it remains unclear whether the IMT effects are attributed to central or peripheral improvement. Previous studies have only used typical parameters, such as respiratory function, respiratory muscle strength, 6MWD, and HRQOL to evaluate the effects of IMT $[15,16,18-20]$.

In this study, we aimed to clarify the effects of IMT and evaluate these effects from multiple perspectives, by using two novel parameters: the airway-occlusion pressure at $0.1 \mathrm{~s}$ after the start of inspiratory flow $\left(P_{0.1}\right)$, as an index of respiratory central output, and the thickness of the diaphragm muscle (Tdi), as a proxy for diaphragm movement, assessed by ultrasound.

\section{Methods}

\section{Participants}

This prospective cohort study included 20 ambulatory patients with COPD who visited Kirigaoka Tsuda Hospital, Fukuoka, Japan, for outpatient rehabilitation in June 2017. A study flow chart is presented in Fig. 1. IMT training for 2 months was possible for 13 outpatient participants ( 11 male, two female; mean age, $72.9 \pm 7.35$ years; height, $160.9 \pm 8.67 \mathrm{~cm}$; body weight, $56.8 \pm 10.6 \mathrm{~kg}$; body mass index, $21.4 \pm 2.6$ $\left.\mathrm{kg} / \mathrm{m}^{2}\right)$.

Patients who could walk without using a cane and did not need to inhale oxygen while walking were included. Patients with severe orthopedic disease, cardiovascular disease, central nervous system disorders, and cognitive impairment were excluded. After obtaining approval from our Institutional Ethics Committee (approval no. 29 - 10 in 2017), the purpose and content of this study, and the method of personal information management, were explained to all participants. All the participants provided written informed consent.

\section{Procedures}

We used a threshold-type IMT device, POWER breathe ${ }^{\circledR}$ Medic Plus (POWER breathe International Ltd., Southam, United Kingdom) (Fig. 2), for IMT in combination with the outpatient rehabilitation regimens.

PImax measurements were performed twice, starting with a load of $20 \%$ of the highest PImax obtained and subsequently increasing the load to $50 \%$. IMT was performed for 30 repetitions twice a day for 2 months, and was recorded every day for 2 months using a checklist. The respiratory function, respiratory muscle strength, $\mathrm{P}_{0.1}, 6 \mathrm{MWD}$, Tdi, and CAT scores were measured before and after 2 months of IMT (Fig. 3).

The peripheral artery oxygen saturation $\left(\mathrm{SpO}_{2}\right)$, heart rate $(\mathrm{HR})$, respiratory rate $(\mathrm{RR})$, as well as dyspnea and lower limb fatigue (using the Borg Scale) were measured before and after the 6-min walk test 
(6MWT). These measurements were also recorded during a 2-min recovery period [21].

\section{Measuring equipment}

\section{Respiratory function}

We used an electronic spirometer (AS-507, Minato Medical Science, Osaka, Japan,) to evaluate respiratory function, vital capacity, forced vital capacity $(\mathrm{FVC}), \mathrm{FEV}_{1.0}$, and $\mathrm{FEV}_{1.0} / \mathrm{FVC}$ ratio $\left(\mathrm{FEV}_{1.0} \%\right)$. For respiratory muscle strength, the PImax and maximum expiratory pressure (PEmax) were used to measure the intraoral pressure $[22,23]$. The PImax at residual capacity in the sitting position and the PEmax at whole lung capacity were measured according to the method described by Black and Hyatt [24]. The participants were maintained pressure for at least $1.5 \mathrm{~s}$ and the maneuver was repeated three times; the respiratory muscle strength was determined as the highest of the three recorded values [25].

\section{$P_{0.1}$ measurement}

$\mathrm{P}_{0.1}$ has been used as an indicator of respiratory center output related to dyspnea [26, 27]. In our study, an airway occlusion system (model 9326, Hans Rudolph, Shawnee, KS, USA; dead space $48.9 \mathrm{~mL}$ ) was used to measure $\mathrm{P}_{0.1}$ (Fig. 4).

Airway pressure was measured using a differential pressure meter (DP-10, Validyne, Northridge, CA, USA), while ventilation parameters were measured using a metabolic gas analyzer (AE-300S, Minato Medical Science). A hot wire flow transducer was connected to the outlet of the airway occlusion system, and a mask (MAS0215, Minato Medical Science) was connected to the mouth port. A differential pressure transducer was connected to the airway occlusion system via a tube (4-mm diameter) to measure the airway pressure. Entrance to the airway obstruction system was manually occluded using a balloon at the end of each expiration and held until the start of inspiration.

The $\mathrm{P}_{0.1}$ measurement was obtained by closing the inhalation port with a balloon shutter at the end of expiration and by measuring the intraoral pressure after $100 \mathrm{~ms}$, when the intraoral pressure became negative at the start of resting inhalation [28]. $P_{0.1}$ was randomly measured five times, and the average calculated from four stable measurements was recorded, as previously reported [29]. Analog signals from raw flow pressure were downloaded to a personal computer via an analog-to-digital converter (PowerLab 16/30, ADInstruments, Sydney, Australia) at a sampling frequency of $1,000 \mathrm{~Hz}$. These signals were analyzed using commercially available software (Chart 5.3, ADInstruments) to calculate $P_{0.1}$. COPD was characterized by decreased inspiratory muscle strength, and $\mathrm{P}_{0.1}$ was corrected to PImax $\left(\mathrm{P}_{0.1} / \mathrm{PImax}\right)$.

\section{Tdi measurement}

The Tdi was measured via a linear probe in B mode using an ultrasonic diagnostic imaging apparatus (ARIETTA Prologue, Hitachi, Ltd., Tokyo, Japan). The measurement position was between the eighth and tenth ribs on the right axillary line. The muscle thickness at the zone of apposition of the diaphragm (the part of the rib diaphragm angle in contact with the chest wall at the origin) was measured by placing a 
probe coated with an ultrasonic gel on the body surface. The parameters measured were resting inspiration, resting expiration, maximal inspiration, and maximal expiration.

\section{MWT}

The 6MWT is a field walking test for assessing exercise capacity and is an essential evaluation item for respiratory rehabilitation. The guidelines for the 6MWT were published by the American Thoracic Society in 2002 [30]. According to these guidelines, the walkway was used by folding back a flat straight course of $30 \mathrm{~m}$, and the participants were instructed to "walk a long distance as fast as possible in $6 \mathrm{~min}$," and a call was made every min. The primary evaluation item of the 6MWT was the 6MWD [30].

\section{CAT}

The CAT is a tool used to comprehensively assess HRQOL. It consists of the following eight items: (1) cough, (2) sputum, (3) breathlessness, (4) shortness of breath during exertion, (5) daily life, (6) selfconfidence in going out (mental), (7) sleep, and (8) vitality [31-34]. The subjective symptoms were evaluated before and after IMT using the CAT questionnaire.

\section{Other measurements}

Dyspnea and lower limb fatigue were assessed using the Borg Scale; the $\mathrm{RR}, \mathrm{SpO}_{2}$, and $\mathrm{HR}$ were measured before and after the 6MWT and after the 1- and 2-min recovery periods.

\section{Statistical analysis}

SPSS version 21.0 (IBM Corporation, Armonk, NY, USA) was used for all statistical analyses. A paired ttest was used to compare the values of each item before and after training and to determine whether there was a correlation between the specific measurement items. All values are expressed as means \pm standard deviations, and statistical significance was set at $P<.05$.

\section{Results}

The changes in respiratory function and respiratory muscle strength before and after 2 months of IMT are presented in Tables 1 and 2 , respectively. FVC, \% FVC, $\mathrm{FEV}_{1.0}, \% \mathrm{FEV}_{1.0}$, expiratory reserve volume, maximum expiratory flow rate at $25 \%$ vital capacity/height, and PImax significantly increased after training $(P=.001, P=.001, P=.019, P=.012, P=.012, P=.033$, and $P=.001$, respectively). The changes in $\mathrm{P}_{0.1}, \mathrm{P}_{0.1} / \mathrm{PImax}, 6 \mathrm{MWD}$, and CAT scores were assessed, and only $\mathrm{P}_{0.1} / \mathrm{PImax}$ significantly decreased after training $(P=.01)$, while the 6MWD significantly increased $(P=.01)$ (Table 3). The changes in the Tdi are presented in Table 4. The changes in the Borg Scale scores for dyspnea and lower limb fatigue, RR, $\mathrm{SpO}_{2}$, and $\mathrm{HR}$ before and after the 6MWT and after the 1- and 2-min recovery periods are presented in Table 5. Resting inspiration, resting expiration, and maximal inspiration significantly increased after training $(P=.008, P=.011, P=.001$, respectively). In contrast, the Borg Scale scores for dyspnea and 
lower limb fatigue and the RR significantly decreased during the 1-min recovery period $(P=.050, P=.016$, and $P=.036$, respectively).

Table 1

Comparison of respiratory function before and after inspiratory muscle training

\begin{tabular}{|c|c|c|c|}
\hline Parameter & Before IMT & After IMT & $P$ value (ES) \\
\hline FVC (L) & $2.15 \pm .76$ & $2.44 \pm .76$ & $.001 *(.85)$ \\
\hline$\% F V C(\%)$ & $68.0 \pm 19.3$ & $77.5 \pm 17.3$ & $.001^{*}(.88)$ \\
\hline $\mathrm{FEV}_{1.0}(\mathrm{~L})$ & $1.36 \pm .60$ & $1.45 \pm .59$ & $.019^{\dagger}(.62)$ \\
\hline$\% \mathrm{FEV}_{1.0}(\%)$ & $53.6 \pm 18.7$ & $57.3 \pm 18.1$ & $.012^{\dagger}(.65)$ \\
\hline $\mathrm{FEV}_{1.0} \%(\%)$ & $59.0 \pm 11.9$ & $59.0 \pm 11.6$ & .979 \\
\hline VC (L) & $2.77 \pm .99$ & $2.78 \pm .81$ & .862 \\
\hline \%VC (\%) & $84.1 \pm 22.0$ & $85.2 \pm 17.0$ & .648 \\
\hline $\mathrm{V}_{\mathrm{T}}(\mathrm{L})$ & $.85 \pm .44$ & $.93 \pm .38$ & .319 \\
\hline IRV (L) & $1.27 \pm .69$ & $1.07 \pm .57$ & .071 \\
\hline $\operatorname{ERV}(\mathrm{L})$ & $.54 \pm .20$ & $.86 \pm .48$ & $.012^{\dagger}(.65)$ \\
\hline $\mathrm{IC}(\mathrm{L})$ & $2.11 \pm .88$ & $2.03 \pm .67$ & .592 \\
\hline $\operatorname{PEFR(L/s)~}$ & $4.01 \pm 2.12$ & $4.48 \pm 2.11$ & .129 \\
\hline MMF(L/s) & $.81 \pm .83$ & $.85 \pm .69$ & .535 \\
\hline $\mathrm{V} 25 / \mathrm{Ht}(\mathrm{L} / \mathrm{s} / \mathrm{m})$ & $.21 \pm .14$ & $.23 \pm .14$ & $.033^{\dagger}(.57)$ \\
\hline \multicolumn{4}{|c|}{ Data are presented as means \pm standard deviations. } \\
\hline \multicolumn{4}{|c|}{ Statistically significant values are marked as follows: ${ }^{\star} P<.001 ; \dagger P<.05$} \\
\hline \multicolumn{4}{|c|}{$\begin{array}{l}\text { ES: effect size; IMT: inspiratory muscle training; FEV1\%: FEV1/FVC ratio; VC: vital capacity; } V_{T} \text {, tidal } \\
\text { volume; IRV, inspiratory reserve volume; ERV: expiratory reserve volume; IC: inspiratory capacity; PEFR: } \\
\text { peak expiratory flow rate; MMF: maximum mid-expiratory flow; V25/Ht: maximum expiratory flow rate } \\
\text { at } 25 \% \text { VC/height }\end{array}$} \\
\hline
\end{tabular}


Table 2

Comparison of the respiratory muscle strength before and after inspiratory muscle training

\begin{tabular}{|lccc|}
\hline Parameter & Before IMT & After IMT & $P$ value (ES) \\
\hline PImax $\left(\mathrm{cmH}_{2} \mathrm{O}\right)$ & $61.1 \pm 25.3$ & $77.3 \pm 21.5$ & $.001 *(.81)$ \\
\hline PEmax $\left(\mathrm{cmH}_{2} \mathrm{O}\right)$ & $68.3 \pm 22.1$ & $87.2 \pm 35.6$ & .063 \\
\hline Data are presented as means \pm standard deviations. & \\
\hline$* P<.001$ & \\
\hline $\begin{array}{l}\text { ES: effect size; IMT: inspiratory muscle training; PImax: maximal inspiratory pressure; PEmax: } \\
\text { maximal expiratory pressure }\end{array}$ & \\
\hline
\end{tabular}

Table 3

Respiratory motor output, 6MWD, and CAT scores before and after IMT

\begin{tabular}{|llll|}
\hline Parameter & Before IMT & After IMT & Pvalue (ES) \\
\hline $\mathrm{P}_{0.1}\left(\mathrm{cmH}_{2} \mathrm{O}\right)$ & $-1.86 \pm .76$ & $-1.84 \pm .79$ & .904 \\
\hline $\mathrm{P}_{0.1} / \mathrm{PImax}(\%)$ & $-3.92 \pm .02$ & $-2.80 \pm .02$ & $.010 *(.71)$ \\
\hline $6 \mathrm{MWD}(\mathrm{m})$ & $354.7 \pm 118.6$ & $384.0 \pm 119.4$ & $.010 *(.66)$ \\
\hline CAT & $12.5 \pm 4.62$ & $12.4 \pm 7.4$ & .962 \\
\hline Data are presented as means \pm standard deviations. & \\
\hline \multirow{2}{*}{$P<.01$} & & \\
\hline $\begin{array}{l}\text { ES: effect size; COPD: chronic obstructive pulmonary disorder; IMT: inspiratory muscle training; } \mathrm{P}_{0.1}: \\
\text { airway-occlusion pressure } 0.1 \mathrm{~s} \text { after the start of inspiratory flow; } \mathrm{P}_{0.1} / \text { PImax: airway-occlusion } \\
\text { pressure } 0.1 \mathrm{~s} \text { after the start of inspiratory flow/maximal inspiratory pressure; 6MWD: 6-min walking } \\
\text { distance; CAT: COPD assessment test }\end{array}$ \\
\hline
\end{tabular}


Table 4

Comparison of diaphragm thickness before and after inspiratory muscle training

\begin{tabular}{|llll|}
\hline Parameter & Before IMT & After IMT & $P$ value (ES) \\
\hline Resting inspiration $(\mathrm{mm})$ & $2.18 \pm .37$ & $2.48 \pm .47$ & $.008^{\star}(.68)$ \\
\hline Resting expiration $(\mathrm{mm})$ & $1.39 \pm .31$ & $1.58 \pm .34$ & $.011^{\dagger}(.65)$ \\
\hline Maximal inspiration $(\mathrm{mm})$ & $3.68 \pm .59$ & $4.88 \pm .78$ & $.001^{\ddagger}(.82)$ \\
\hline Maximal expiration $(\mathrm{mm})$ & $1.12 \pm .31$ & $1.25 \pm .23$ & .089 \\
\hline Data are presented as means \pm standard deviations. & \\
\hline Statistically significant results are marked as follows: ${ }^{*} P<.01 ; \dagger P<.05 ; \ddagger P<.001$ \\
\hline ES: effect size; IMT: inspiratory muscle training & \\
\hline
\end{tabular}


Table 5

Comparison of Borg Scale scores, $\mathrm{RR}, \mathrm{SpO}_{2}$, and HR during 6MWD before and after IMT

\begin{tabular}{|c|c|c|c|c|}
\hline Parameter & & Before & After & $P$ value \\
\hline \multirow[t]{4}{*}{ Borg scale: dyspnea } & Rest & $.92 \pm 1.06$ & $.77 \pm .70$ & .651 \\
\hline & After 6MWD & $3.23 \pm 1.87$ & $2.81 \pm 2.03$ & .236 \\
\hline & Recovery 1 min & $2.40 \pm 1.35$ & $1.60 \pm 1.17$ & $.050 *(.60)$ \\
\hline & Recovery 2 min & $1.10 \pm .70$ & $1.30 \pm 1.03$ & .509 \\
\hline \multirow[t]{4}{*}{ Borg scale: lower limb fatigue } & Rest & $.65 \pm 1.54$ & $.23 \pm .60$ & .389 \\
\hline & After 6MWD & $2.00 \pm 1.67$ & $2.00 \pm 1.66$ & .888 \\
\hline & Recovery 1 min & $2.00 \pm 1.56$ & $1.05 \pm 1.30$ & $.016 *(.70)$ \\
\hline & Recovery 2 min & $1.15 \pm .81$ & $.80 \pm 1.14$ & .132 \\
\hline \multirow[t]{4}{*}{ RR (times/min) } & Rest & $24.0 \pm 4.62$ & $21.8 \pm 5.75$ & .126 \\
\hline & After 6MWD & $29.0 \pm 5.01$ & $26.2 \pm 4.19$ & .128 \\
\hline & Recovery $1 \mathrm{~min}$ & $25.8 \pm 4.47$ & $22.1 \pm 5.21$ & $.036 *(.63)$ \\
\hline & Recovery 2 min & $23.2 \pm 4.91$ & $21.1 \pm 5.78$ & .173 \\
\hline \multirow[t]{4}{*}{$\mathrm{SpO}_{2}(\%)$} & Rest & $94.9 \pm 2.14$ & $95.0 \pm 2.27$ & .901 \\
\hline & After 6MWD & $91.7 \pm 3.33$ & $92.0 \pm 2.58$ & .613 \\
\hline & Recovery 1 min & $94.3 \pm 2.36$ & $94.6 \pm 2.00$ & .496 \\
\hline & Recovery 2 min & $95.7 \pm 1.64$ & $95.8 \pm 14.0$ & .758 \\
\hline \multirow[t]{4}{*}{ HR (times/min) } & Rest & $76.4 \pm 9.22$ & $75.3 \pm 10.9$ & .588 \\
\hline & After 6MWD & $99.4 \pm 12.5$ & $98.3 \pm 12.4$ & .618 \\
\hline & Recovery 1 min & $82.0 \pm 9.32$ & $83.9 \pm 14.6$ & .632 \\
\hline & Recovery 2 min & $78.0 \pm 11.3$ & $78.9 \pm 12.2$ & .810 \\
\hline \multicolumn{5}{|c|}{ Data are presented as means \pm standard deviations. } \\
\hline \multicolumn{5}{|l|}{ *Statistically significant, $P<.05$} \\
\hline \multicolumn{5}{|c|}{$\begin{array}{l}\text { ES: effect size; IMT: inspiratory muscle training; } \mathrm{SpO}_{2} \text { : oxygen saturation of peripheral artery; HR: } \\
\text { heart rate; RR: respiratory rate; } 6 \mathrm{MWD} \text { : 6-min walking distance }\end{array}$} \\
\hline
\end{tabular}


A positive correlation with PImax was observed for height $(r=.676, P=.011)$, weight $(r=.711, P=.006)$, vital capacity $(r=.646, P=.017)$, inspiratory reserve volume $(r=.766, P=.002)$, inspiratory capacity $(r$ $=.764, P=.002)$, peak expiratory flow rate $(r=.663, P=.013)$, and $\mathrm{P}_{0.1} / \mathrm{PImax}(\mathrm{r}=.759, P=.003)$. A positive correlation with 6MWD was found for $\mathrm{FEV}_{1.0} \%(r=.580, P=.038)$ and $\mathrm{SpO}_{2}$ (1-min recovery) $(r$ $=.701, P=.024)$, while a negative correlation was observed with the Borg Scale dyspnea score (after the 6MWT) $(r=-.687, P=.009)$. A positive correlation with $\mathrm{P}_{0.1}$ was found for $\mathrm{P}_{0.1} / \mathrm{PImax}(\mathrm{r}=.941, P=.000)$.

\section{Discussion}

In this study, we used the improved version of the POWER breathe model, POWER breathe ${ }^{\circledR}$ MEDIC PLUS, to evaluate the combination of IMT with individual training conducted during outpatient rehabilitation. PImax and 6MWD significantly increased. Regarding the Tdi, resting inspiration, resting expiration, and maximal inspiration also increased significantly after training. The Borg Scale scores and RR were significantly lower during the 1-min recovery period following the 6MWT. The loading pressure increased from $20-50 \%$ of the PImax, and IMT was performed 30 times, twice a day, for 2 months. IMT load pressure was classified as follows: low-strength load (low load), $<30 \%$ of the PImax; moderate-pressure load (medium load), $30 \%$ to $<60 \%$ of the PImax; and high-strength pressure load (high load), $\geq 60 \%$ of the PImax [35-37]. For IMT, the optimum load pressure, at which an effect is reliably obtained, is a medium load of $\geq 30 \%$ of the PImax $[35,38]$. At present, performing IMT for 15 min twice a day at a load pressure of $\geq 30 \%$ of the PImax is a standard practice for patients with COPD [35]. However, it was reported that IMT focused on the number of sessions, and not on the duration, and that the maximum inspiratory pressure increased during one session, in which training was performed 30 times [9]. Considering previous reports [35,38], in this study we increased the load pressure from $20-50 \%$ and asked the participants to perform 30 repetitions twice a day. Interestingly, improvements were also observed in the PImax and 6MWD, similar to the results of the meta-analysis conducted by Beaumont et al. [16].

An ultrasound imaging system has recently been established as a method for evaluating diaphragm movement, in which Tdi can be measured in the B mode [39-41]. Baria et al. [42] reported that there was no significant difference in Tdi between patients with COPD and healthy individuals, and also reported a lower limit of normal muscle thickness at rest (i.e., $1.5 \mathrm{~mm}$ ) in both healthy individuals and patients with COPD.

Furthermore, it has been reported that Tdi increases with an increase in pulmonary volume in healthy individuals [43,44] and that Tdi decreases significantly in diaphragmatic paralysis [45]. In our study, the resting muscle thickness was $1.39 \mathrm{~mm}$, which was comparable to that reported in a previous study [42]. Additionally, there was a significant increase in resting inspiration, resting expiration, and maximal inspiration after training. This resulted from an increase in FVC and FEV1.0; therefore, in our view, training improved respiratory function and increased Tdi. 
In this study, the Tdi was measured using ultrasound before and after IMT, and it was confirmed that IMT affected the respiratory muscle strength, respiratory function, and Tdi. DiNino et al. [46] reported that Tdi assessment could be a criterion for ventilator weaning. Thus, we consider that Tdi evaluation may be used as an index for respiratory rehabilitation in the future.

In an ATS/ERS systematic review [47], there was a moderate to strong correlation (coefficient .38-.85) between the 6MWD and physical activity and a strong correlation between low 6MWD (300-450 m) and high mortality; however, prognosis was poor when the 6MWD was $<300 \mathrm{~m}$. The results of our study demonstrated that 6MWD increased significantly after training; although the 6MWD was classified as low, an increase from 354 to $384 \mathrm{~m}$ was observed. A further increase in 6MWD is desirable.

The CAT is an eight-item questionnaire that can be used to comprehensively evaluate patients' HRQOL, and has a clear and strong correlation with St George's Respiratory Questionnaire, which is widely used in the evaluation of quality of life in clinical trials [34]. It has been translated and used in several countries worldwide, including Japan; the same correlation was shown for the Japanese version, which was previously validated [31]. There were no significant differences in the CAT scores before and after training in our study. These results suggested that although the performance of IMT for 2 months improved the respiratory muscle strength and 6MWD, it did not lead to improvement in HRQOL.

The normal range of $P_{0.1}$ is $1-2 \mathrm{cmH}_{2} \mathrm{O}[28,48]$, and it increases with increased respiratory central activity. In patients with COPD, the value is much higher than that in healthy individuals [49,50], and increases with COPD severity [51]. The $\mathrm{P}_{0.1} / \mathrm{PImax}$ index is obtained by normalizing the $\mathrm{P}_{0.1}$ based on differences in inspiratory muscle strength among individuals. $\mathrm{P}_{0.1}$ and $\mathrm{P}_{0.1} / \mathrm{PImax}$ are used as prediction indicators for weaning [52] and are regarded as a more accurate predictor compared to PImax [52]. A recent study using $\mathrm{P}_{0.1}$ for COPD showed that $\mathrm{P}_{0.1}$ and $\mathrm{P}_{0.1} /$ PImax significantly increased when the severity increased in various relaxation positions [53]; interestingly, we obtained similar results. In our study, there was no significant difference in $\mathrm{P}_{0.1}$ before and after training, but a significant decrease in $\mathrm{P}_{0.1} /$ PImax was observed, reflecting the increase in the PImax. In addition, as no significant difference was observed in $\mathrm{P}_{0.1}$, we considered that the improvement in respiratory function by IMT was probably attributed to improvements in peripheral rather than in central functions. This was also supported by a previous study using $\mathrm{P}_{0.1}$ before and after manual chest wall compression in patients with COPD, which showed that $\mathrm{VO}_{2}, \mathrm{VCO}_{2}$, and dyspnea severity significantly decreased after chest compression, whereas $\mathrm{P}_{0.1}$ and $\mathrm{P}_{0.1} / \mathrm{PImax}$ did not change [54]. Improvement in respiratory function and dyspnea because of manual chest wall compression may be attributed to peripheral rather than central improvement [54].

Dyspnea improvement is also important in respiratory rehabilitation. The dyspnea sensing mechanism includes not only chemoreceptors and mechanoreceptors, but also motor command [55] and neuromechanical dissociation [56, 57], involving various factors, such as motor outputs and sensory projections in the central nervous system [58]. Polkey et al. [59] reported that classic IMT may control muscle and central circuits and is particularly useful for patients with neurological disorders and for 
those with reduced lung volume because of stroke [59]. However, it remains unclear whether dyspnea improvement and IMT effects are central or peripheral. In this study, during the 1-min recovery period following the 6MWT, the Borg Scale scores for dyspnea and lower limb fatigue and the RR significantly decreased. Furthermore, a negative correlation was found between the 6MWD and the Borg Scale dyspnea score (after the 6MWT), suggesting that dyspnea is one of the factors that limit performance in the 6MWT. Therefore, dyspnea improvement is necessary for continuous movement. Moreover, the fact that the PImax, 6MWD, and Tdi significantly increased while $\mathrm{P}_{0.1}$ did not change after IMT further suggested that the IMT effects are attributed to improvements in peripheral factors rather than to improvements of central factors.

One of the strengths of this study was the finding that the improvement in respiratory function by IMT was likely to be attributed to peripheral factors. Elucidating whether improvements in dyspnea and respiratory function are attributed to central or peripheral components would contribute to the design of more effective respiratory rehabilitation intervention methods, help determine more accurately the effects of respiratory rehabilitation, and help identify more appropriate candidates for rehabilitation.

This study had several limitations, including the small sample size, outpatient-based IMT, lack of a control group, patient compliance validation, and technical outcome measurements. In a future research, we will further increase the number of participants and use a control group to examine the differences among different IMT devices.

\section{Conclusion}

We examined the effects of IMT in combination with individual training and evaluated the $\mathrm{P}_{0.1}$ and Tdi. We observed a significant increase in PImax and 6MWD, and an improvement in Tdi. However, there was no significant difference in $\mathrm{P}_{0.1}$, suggesting that the effect of IMT was attributed to the improvement of peripheral factors rather to the improvement of central factors.

\section{Abbreviations}

IMT: inspiratory muscle training

HRQOL: health-related quality of life

COPD: chronic obstructive pulmonary disease

GOLD: Global Initiative for Chronic Obstructive Lung Disease

PImax: maximal inspiratory pressure

6MWD: 6-min walking distance

$\mathrm{FEV}_{1.0}$ : forced expiratory volume in $1 \mathrm{~s}$ 
FVC: forced vital capacity

6MWT: 6-min walking distance test

$P_{0.1}$ : airway-occlusion pressure $0.1 \mathrm{~s}$ after the start of inspiratory flow

Tdi: thickness of the diaphragm muscle

CAT: COPD assessment test

$\mathrm{SpO}_{2}$ : peripheral artery oxygen saturation

HR: heart rate

RR: respiratory rate

PEmax: maximum expiratory pressure

\section{Declarations}

\section{Ethics approval and consent to participate}

The study protocol was approved by the Institutional Ethics Committee (approval no. 29-10) in 2017. All the subjects provided written informed consent.

\section{Consent for publication}

Not applicable.

\section{Availability of data and materials}

Data sets used and/or analyzed during the current study are available from the corresponding authors upon reasonable request.

\section{Competing interests}

The authors declare that they have no competing interests.

\section{Funding}

This project received no funding.

\section{Author contributions}

TI searched the literature, performed the statistical analysis, and drafted the manuscript. TM helped design the study, collected data, and assisted with preparing the manuscript. TT participated in the 
design of the study and helped improve the manuscript. TK participated in the design and coordination of the study and reviewed the manuscript. All authors have read and approved the manuscript submitted for review and publication.

\section{Acknowledgements}

The authors are grateful to the outpatients at Kirigaoka Tsuda Hospital who participated in this study.

\section{References}

1. Spruit MA, Singh SJ, Garvey C, ZuWallack R, Nici L, Rochester C, et al. An official American Thoracic Society/European Respiratory Society statement: key concepts and advances in pulmonary rehabilitation. Am J Respir Crit Care Med. 2013;188:e13-64.

2. Smith K, Cook D, Guyatt GH, Madhavan J, Oxman AD. Respiratory muscle training in chronic airflow limitation: a meta-analysis. Am Rev Respir Dis. 1992;145:533-9.

3. Lötters F, van Tol B, Kwakkel G, Gosselink R. Effects of controlled inspiratory muscle training in patients with COPD: a meta-analysis. Eur Respir J. 2002;20:570-6.

4. Ries AL, Bauldoff GS, Carlin BW, Casaburi R, Emery CF, Mahler DA, et al. Pulmonary rehabilitation: joint ACCP/AACVPR evidence-based clinical practice guidelines. Chest. 2001;131:4S-42S.

5. Monteiro SG, Pessolano FA, Suárez AA, De Vito EL. Study of diaphragmatic muscle function during abdominal weight in normal subjects. Medicina (B Aires). 2012;72:98-102.

6. Lin $\mathrm{KH}$, Chuang $\mathrm{CC}$, Wu HD, Chang $\mathrm{CW}$, Kou YR. Abdominal weight and inspiratory resistance: their immediate effects on inspiratory muscle functions during maximal voluntary breathing in chronic tetraplegic patients. Arch Phys Med Rehabil. 1999;80:741-5.

7. Larson JL, Kim MJ, Sharp JT, Larson DA. Inspiratory muscle training with a pressure threshold breathing device in patients with chronic obstructive pulmonary disease. Am Rev Respir Dis. 1988;138:689-96.

8. Charususin N, Gosselink R, Decramer M, McConnell A, Saey D, Maltais F, et al. Inspiratory muscle training protocol for patients with chronic obstructive pulmonary disease (IMTCO study): a multicentre randomized controlled trial. BMJ Open. 2013;3:e003101.

9. Langer D, Charususin N, Jácome C, Hoffman M, McConnell A, DeCramer M, et al. Efficacy of a novel method for inspiratory muscle training in people with chronic obstructive pulmonary disease. Phys Ther. 2015;95:1264-73.

10. Geddes EL, Reid WD, Crowe J, O'Brien K, Brooks D. Inspiratory muscle training in adults with chronic obstructive disease: a systematic review. Respir Med. 2005;99:1440-58.

11. O'Brien K, Geddes EL, Reid WD, Brooks D, Crowe J. Inspiratory muscle training compared with other rehabilitation interventions in chronic obstructive pulmonary disease. a systematic review update. $\mathrm{J}$ Cardiopulm Rehabil Prev. 2008;28:128-41. 
12. Budweiser S, Moertl M, Jörres RA, Windisch W, Heinemann F, Pfeifer M. Respiratory muscle training in restrictive thoracic disease: a randomized controlled trial. Arch Phys Med Rehabil. 2006;87:1559-65.

13. Wanke T, Toifl K, Merkle M, Formanek D, Lahrmann H, Zwick H. Inspiratory muscle training in patients with Duchenne muscular dystrophy. Chest. 1994;105:475-82.

14. Vilozni D, Bar-Yishay E, Gur I, Shapira Y, Meyer S, Godfrey S. Computerized respiratory muscle training in children with Duchenne muscular dystrophy. Neuromusc Disord. 1994;4:249-55.

15. Gosselink R, De Vos J, van den Heuvel SP, Segers J, Decramer M, Kwakkel G. Impact of inspiratory muscle training in patients with COPD: what is the evidence? Eur Respir J. 2011;37:416-25.

16. Beaumont M, Forget P, Couturaud F, Reychler G. Effects of inspiratory muscle training in COPD patients. A systematic review and meta-analysis. Clin Respir J. 2018;12:1-11.

17. Langer D, Ciavaglia C, Faisal A, Webb KA, Neder JA, Gosseling R, et al. Inspiratory muscle training reduces diaphragm activation and dyspnea during exercise in COPD. J Appl Physiol. 2018;125:38192.

18. Charususin N, Gosselink R, Decramer M, Demeyer H, McConnell A, Saey D, et al. Randomised controlled trial of adjunctive inspiratory muscle training for patients with COPD. Thorax. 2018;73:942-50.

19. Beaumont M, Mialon P, Le Ber C, Le Mevel P, Péran L, Meurisse O, et al. Effects of inspiratory muscle training on dyspnoea in severe COPD patients during pulmonary rehabilitation: controlled randomised trial. Eur Respir J. 2018;51:1701107.

20. Schultz K, Jelusic D, Wittmann M, Krämer B, Huber V, Fuchs S, et al. Inspiratory muscle training does not improve clinical outcomes in 3-week COPD rehabilitation: results from a randomised controlled trial. Eur Respir J. 2018;51:1702000.

21. Ichiba T, Miyagawa T, Tsuda T. Effect of inspiratory muscle training in patients with COPD. Respir Care. 2018;63:3025383.

22. Polkey MI, Green M, Moxham J. Measurement of respiratory muscle strength. Thorax. 1995;50:1131-5.

23. Syabbalo N. Assessment of respiratory muscle function and strength. Postgrad Med J. 1998;74:208-15.

24. Black LF, Hyatt RE. Maximal respiratory pressures: normal values and relationships to age and sex. Am Rev Respir Dis. 1969;99:696-702.

25. American Thoracic Society/European Respiratory Society: ATS/ERS Statement on respiratory muscle testing. Am J Respir Crit Care Med. 2002;166:518-624.

26. Manning HL, Schwartzstein RM. Pathophysiology of dyspnea. N Engl J Med. 1995;333:1547-53.

27. Milic-Emili J, Whitelaw WA, Derenne JP. New tests to assess lung function: occlusion pressure-a simple measure of the respiratory center's output. N Engl J Med. 1975;293:1029-30.

28. Whitelaw WA, Derenne JP. Airway occlusion pressure. J Appl Physiol. 1993;74:1475-83. 
29. Kera T, Aihara A, Inomata T. Reliability of airway occlusion pressure as an index of respiratory motor output. Respir Care. 2013;58:845-9.

30. ATS Committee on Proficiency Standards for Clinical Pulmonary Function Laboratories. ATS statement: guidelines for the six-minute walk test. Am J Respir Crit Care Med. 2002;166:111-7.

31. Tsuda T, Suematsu R, Kamohara K, Kurose M, Arakawa I, Tomioka R, et al. Development of the Japanese version of the COPD Assessment Test. Respir Investig. 2012;50:34-9.

32. Mackay AJ, Donaldson GC, Patel AR, Jones PW, Hurst JR, Wedzicha JA. Usefulness of the chronic obstructive pulmonary disease assessment test to evaluate severity of COPD exacerbations. Am J Respir Crit Care Med. 2012;185:1218-24.

33. Jones PW, Tabberer M, Chen WH. Creating scenarios of the impact of COPD and their relationship to COPD Assessment Test (CAT TM) scores. BMC Pulm Med. 2011;11:42.

34. Jones PW, Harding G, Berry P, Wiklund I, Chen WH, Kline Leidy N. Development and first validation of the COPD Assessment Test. Eur Respir J. 2009;34:648-54.

35. Larson JL, Kim MJ, Sharp JT, Larson DA. Inspiratory muscle training with a pressure threshold breathing device in patients with chronic obstructive pulmonary disease. Am Rev Respir Dis. 1988;138:689-96.

36. Hill K, Jenkins SC, Phillippe DL, Cecins N, Shepherd KL, Green DJ, et al. High-intensity inspiratory muscle training in COPD. Eur Respir J. 2006;27:1119-28.

37. Villafranca C, Bozone G, Leiva A, Lisboa C. Effect of inspiratory muscle training with an intermediate load on inspiratory muscle power. Eur Respir J. 1998;11:28-33.

38. Crowe J, Reid WD, Geddes EL, O'Brien K, Brooks D. Inspiratory muscle training compared with other rehabilitation interventions in adults with chronic obstructive pulmonary disease: a systematic literature review and meta-analysis. COPD. 2005;2:319-29.

39. Boon AJ, Harper CJ, Ghahfarokhi LS, Stommen JA, Watson JC, Sorenson EJ. Two-dimensional ultrasound imaging of the diaphragm: quantitative values in normal subjects. Muscle Nerve. 2013;47:884-9.

40. Baldwin CE, Paratz JD, Bersten AD. Diaphragm and peripheral muscle thickness on ultrasound: intrarater reliability and variability of a methodology using non-standard recumbent positions. Respirology. 2011;16:1136-43.

41. Harper CJ, Shahgholi L, Cieslak K, Hellyer NJ, Strommen JA, Boon AJ. Variability in diaphragm motion during normal breathing, assessed with B-mode ultrasound. J Orthop Sports Phys Ther. 2013;43:927-31.

42. Baria MR囚Shahgholi L囚Sorenson EJ囚Harper CJ, Lim KG, Strommen JA, et al. B囚mode ultrasound assessment of diaphragm structure and function in patients with COPD. Chest. 2014;146:680-5.

43. Wait JL, Nahormek PA, Yost WT, Rochester DP. Diaphragmatic thickness囚lung volume relationship in vivo. J Appl Physiol. 1989; 67:1560-8. 
44. Cohn D, Benditt JO, Eveloff S, McCool FD. Diaphragm thickening during inspiration. J Appl Physiol. 1997;83:291-6.

45. Summerhill EM, El-Sameed YA, Glidden TJ, McCool FD. Monitoring recovery from diaphragm paralysis with ultrasound囚Chest. 2008;133:737-3.

46. DiNino E\Gartman EJ囚Sethi JM®McCool FD. Diaphragm ultrasound as a predictor of successful extubation from mechanical ventilation. Thorax. 2014;69:423-7.

47. Singh SJ, Puhan MA, Andrianopoulos V, Hernandes NA, Mitchell KE, Hill CJ, et al. An official systematic review of the European Respiratory Society/American Thoracic Society: measurement properties of field walking tests in chronic respiratory disease. Eur Respir J. 2014;44:1447-78.

48. Whitelaw WA, Derenne JP, Millc-Emili J. Occlusion pressure as a measure of respiratory center output in conscious man. Respir Physiol. 1975;23:181-99.

49. Erbland ML, Ebert RV, Snow SL. Interaction of hypoxia and hypercapnia on respiratory drive in patients with COPD. Chest. 1990;97:1289-94.

50. Marin JM, Motnes de Oca M, Rassulo J, Celli BR. Ventilatory drive at rest and perception of exertional dyspnea in severe COPD. Chest. 1999;115:1293-300.

51. Montes de Oca $\mathrm{M}$, Celli BR. Mouth occlusion pressure, $\mathrm{CO}_{2}$ response and hypercapnia in severe chronic obstructive pulmonary disease. Eur Respire J. 1998;12:666-71.

52. Nemer SN, Barbas CS, Caldeira JB, Guimarães B, Azeredo LM, Gago R, et al. Evaluation of maximal inspiratory pressure, tracheal airway occlusion pressure, and its ratio in the weaning outcome. $J$ Crit Care. 2009;24:441-6.

53. Ichiba T, Yamada T, Miyagawa T, Kera T, Tsuda T, Kokubu F, et al. Efficacy of relaxation posture in patients with chronic obstructive pulmonary disease. Respir Care. 2010;20:146-51.

54. Ichiba T, Miyagawa T, Kera T, Tsuda T. Effect of manual chest wall compression in participants with chronic obstructive pulmonary disease. J Phys Ther Sci. 2018;30;1349-54.

55. Killian KJ, Gandevia SC, Summers E, Campbell EJ. Effect of increased lung volume on perception of breathlessness, effort, and tension. J Appl Physiol Respir Environ Exerc Physiol. 1984;57:686-91.

56. O'Donnell DE. Breathlessness in patients with chronic airflow limitation. Mechanisms and management. Chest. 1994;106:904-12.

57. O’Donnell DE, Banzett RB, Carrieri-Kohlman V, Casaburi R, Davenport PW, Gandevia SC, et al. Pathophysiology of dyspnea in chronic obstructive pulmonary disease: a roundtable. Proc Am Thorac Soc. 2007;4:145-68.

58. Kera T, Aihara A, Ichiba T. Respiratory rehabilitation approach from the viewpoint of dyspnea sensing model. Physiotherapy-Clinic Research Education. 2011;18:9-14.

59. Polkey MI, Ambrosino N. Inspiratory muscle training in COPD: can data finally beat emotion? Thorax. 2018;73:900-1.

\section{Figures}




\section{Enrollment}

Assessed for eligibility $(n=22)$

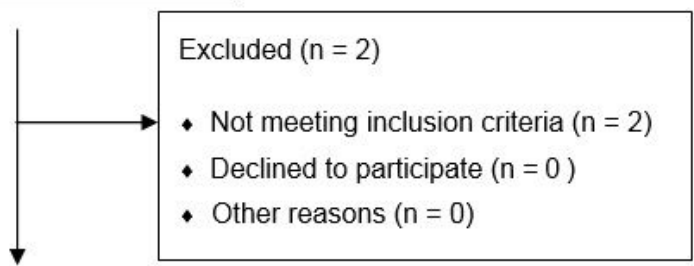

Follow-Up 1 - Received allocated intervention $(n=20)$

\section{Figure 1}

\section{Study flowchart}




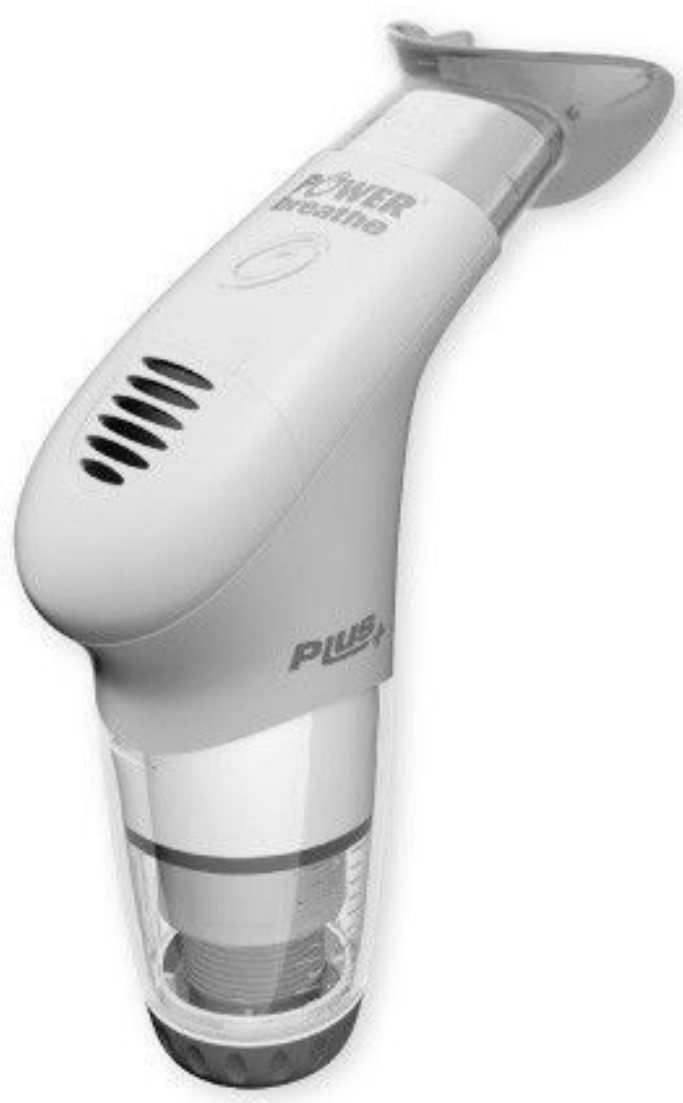

Figure 2

Inspiratory muscle training device, POWER breathe ${ }^{\circledR}$ Medic Plus 


\section{Pre-IMT training \\ Post-IMT training}

Thirty repetitions of IMT are performed twice a day for 2 months and recorded every day for 2 months on a checklist.
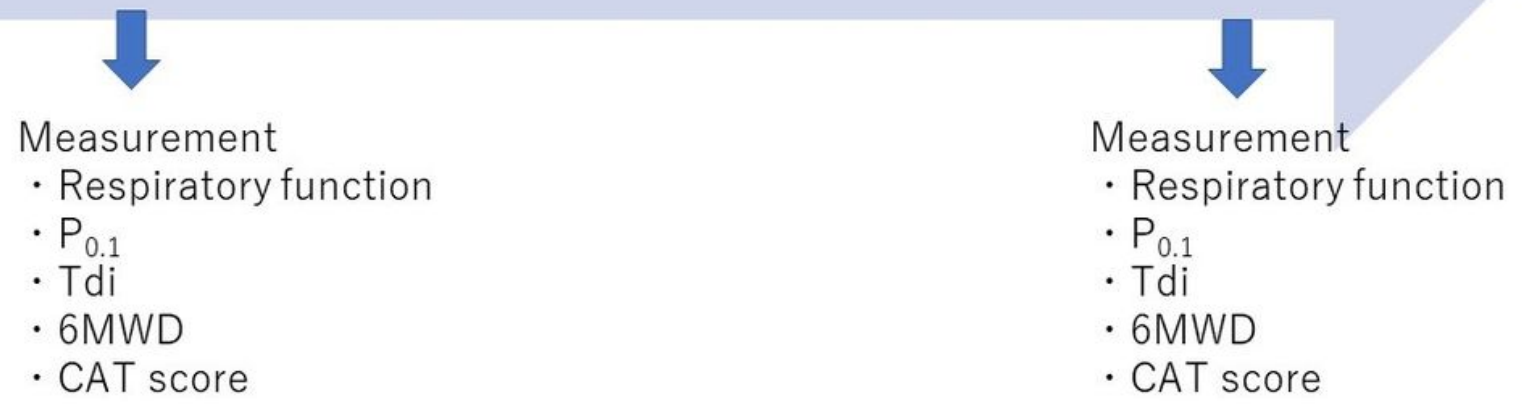

Figure 3

Study design diagram P0.1: the airway-occlusion pressure $0.1 \mathrm{~s}$ after the start of inspiratory flow; Tdi: thickness of the diaphragm muscle; 6MWD: 6-min walking distance; CAT: COPD assessment test

An airway occulsion system
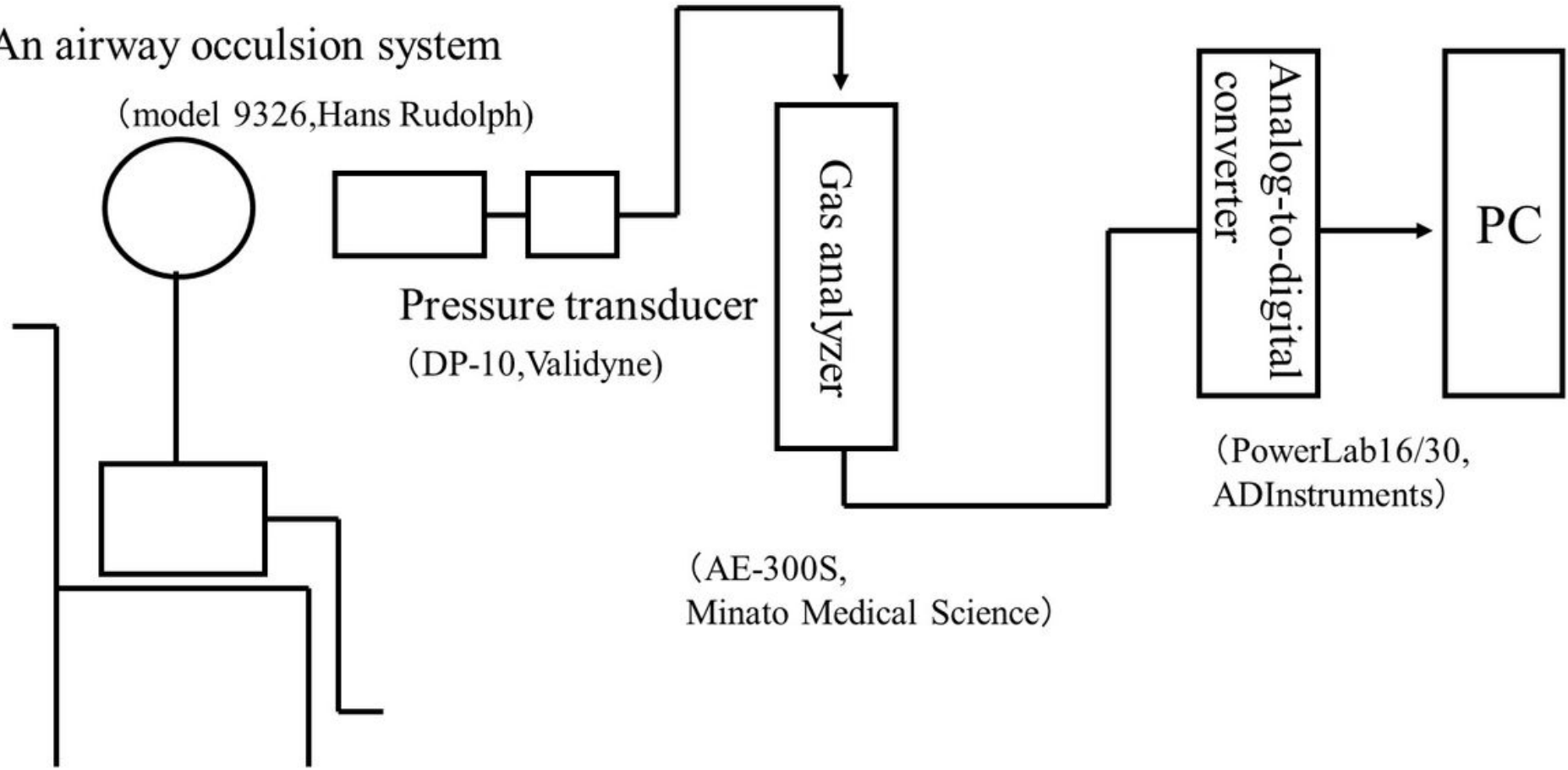

(PowerLab16/30, ADInstruments)

(AE-300S,

Minato Medical Science)

Figure 4 
Measuring equipment. P0.1 Measuring Device: The pressure transducer is connected to the side port of the airway occlusion system to measure intraoral pressure, and the hot wire flow transducer of the expiratory gas analyzer is connected to the expiratory port. The exhaled gas analyzer analog signal and pressure transducer readings are continuously recorded using an analog-to-digital converter; PC: personal computer 